\title{
BMJ open Publication trends in newspapers and scientific journals for SSRIs and suicidality: a systematic longitudinal study
}

\author{
J F Hernandez, ${ }^{1}$ A K Mantel-Teeuwisse, ${ }^{1}$ G J M W van Thiel, ${ }^{2} \mathrm{~S}$ V Belitser, ${ }^{1}$ \\ J A M Raaijmakers, ${ }^{1,3}$ T Pieters ${ }^{1,4}$
}

To cite: Hernandez JF, Mantel-Teeuwisse AK, van Thiel GJMW, et al. Publication trends in newspapers and scientific journals for SSRIs and suicidality: a systematic longitudinal study. BMJ Open 2011:1:e000290. doi:10. 1136/bmjopen-2011-000290

- Prepublication history for this paper is available online. To view these files please visit the journal online (http:// bmjopen.bmj.com/content/ early/recent).

Received 5 August 2011 Accepted 23 September 2011

This final article is available for use under the terms of the Creative Commons Attribution Non-Commercial 2.0 Licence; see http://bmjopen.bmj.com

\section{${ }^{1}$ Department of}

Pharmacoepidemiology \& Clinical Pharmacology, Utrecht Institute for Pharmaceutical Sciences (UIPS), Utrecht University, Utrecht, the Netherlands 2Julius Centre for Health Sciences and Primary Care, University Medical Centre Utrecht, Utrecht, the Netherlands

${ }^{3}$ External Scientific

Collaborations Europe GlaxoSmithKline, Zeist, the Netherlands

${ }^{4} E M G O$, VU Medical Centre, Amsterdam, the Netherlands

Correspondence to Professor Dr T Pieters; t.pieters@uu.nl

\section{ABSTRACT}

Background: In the period 2003-2008, the regulatory authorities issued several warnings restricting the use of selective serotonin re-uptake inhibitors (SSRIs) in paediatrics, in reaction to safety concerns regarding the risk of suicidality. In this study, the SSRIs and suicidality controversy serves as a template to analyse the long-term publication trends regarding the benefit/ risk profile of medications. The aim is to ascertain differences (in terms of numbers, categories and timing) between negative and positive newspaper and journal articles on SSRIs and suicidality and to ascertain correlations between changes in the reports and regulatory warnings.

Methods: A systematic review of scientific articles (Embase) and the Netherlands (NL) and the UK newspapers (LexisNexis) was performed between 2000 and 2010. Categorisation was done by 'effect' (related treatment effect), 'type of article' and 'age group'. The articles' positive-to-negative effect ratio was determined. Differences in distribution of effect categories were analysed across sources, type of article and age group using the Mann-Whitney (two subgroups) or Kruskal-Wallis test (three or more).

Findings: In total, 1141 articles were categorised: 352 scientific, 224 Dutch and 565 British newspaper articles. Scientific articles were predominantly on research and were positive, whereas newspaper articles were negative (ratios $=3.50$ - scientific, $0.69-N L$ and $0.94-U K ; p<0.001)$. Articles on paediatrics were less positive in scientific journals and more negative in newspapers (ratios $=2.29$ - scientific, 0.26 -NL and $0.20-\mathrm{UK} ; \mathrm{p}<0.001$ ), while articles on adults were positive overall (ratios $=10.0$ - scientific, 1.06-NL and 1.70-UK; $p<0.001$ ). In addition, negative-effect reporting trends were exacerbated following regulatory warnings and were generally opinion articles, both in scientific journals and in newspapers (2003/2004 and after 2007).

Interpretation: The authors found a positive publication tendency inherent in journal research articles. This apparent positive publication bias present in scientific journals, however, does not seem to prevent the dissemination of 'bad' news about medications. The negative tendency present in Dutch and British newspapers was perceivable in the

\section{ARTICLE SUMMARY}

Article focus

- Publication trends of the benefit/risk profile of medications might differ in time and during a drug safety case.

- We analysed the long-term dynamics of publication trends in the context of the SSRIs and suicidality controversy.

- The number of articles (in terms of positive, negative and neutral, as well as the type of article and age groups) were analysed in scientific journals and the Netherlands and the UK dailies from January 2000 to December 2009.

Key messages

- We found a positive publication tendency in scientific journals that did not influence the dissemination of negative news in newspapers in the Netherlands and the UK.

- The negative tendency in newspapers was predominant in paediatrics and during the warnings.

n The public was informed on time about this drug safety controversy, although the information conveyed was not uniform (from scientific journals to newspapers).

Strengths and limitations of this study

- Definition of the categories is limited by the researchers' criteria.

- Two independent scorers reviewed the articles to avoid subjectivity during scoring.

- More than 95\% agreements between both research scorers were documented.

paediatrics group and during the warnings, indicating that national news media have informed the public about this international drug safety controversy on time.

\section{INTRODUCTION}

The news media are an important source of information about therapeutic drugs and health. ${ }^{1}$ Coverage varies from 
communicating the benefits and risks of medications to drug regulation and litigation, among others. ${ }^{2}{ }^{3}$ Scientific journals are a significant source of information for journalists writing about medicine. ${ }^{4}$ However, this does not necessarily mean that 'good' or 'bad' news about medicines in the news media is determined by the scientific literature. ${ }^{45}$ The good and bad news in both news media and scientific and medical journals may be in agreement but may also differ dramatically depending on the situation. ${ }^{6} 7$

Healthcare providers and consumers alike seek medical information from the news media and act on it accordingly, changing their perceptions and behaviour. ${ }^{8}{ }^{9}$ Coverage of medical news exemplifies how information from the news media and scientific journals can have a significant impact, yet be confusing. ${ }^{710} 11$ Most newspapers' coverage studies of the benefits and risks of medications, although valuable, are short-term and lack a comparative perspective among countries. ${ }^{2} 812$ In this study, we analysed the long-term publication trends regarding the benefit/risk profile of medications in the context of the selective serotonin re-uptake inhibitors (SSRIs) and suicidality controversy (see box 1) from 2000 to 2010 in scientific journals and newspapers in the Netherlands (NL) and in the UK. The aim is to ascertain the differences (in terms of numbers, categories and timing) between negative and positive newspaper and scientific journal articles on SSRIs and suicidality.

\section{Box 1 The SSRIs and suicidality controversy}

In the period 2003-2008, regulatory authorities (Food and Drug Administration (FDA), Medicines and Healthcare products Regulatory Agency (MHRA) and European Medicines Agency (EMA), among others) issued several warnings restricting the use of SSRIs in paediatrics, in reaction to safety concerns regarding suicidal ideation. ${ }^{13-15}$ While some scientists adulated the warnings, others expressed their concerns about the implied consequences. ${ }^{16}{ }^{17}$ The safety issue arose following GlaxoSmithKline's (GSK) request for a 6-month market exclusivity extension with the FDA for the use of paroxetine (an SSRI) to treat paediatric depression in response to the Food and Drug Administration Modernization Act. Consequently, GSK submitted the results from unpublished paediatric clinical data to the FDA. Meanwhile, the BBC aired a documentary entitled 'The secrets of Seroxat' on 13 October 2002 in which it was alleged that internal documents of GSK showed that the dissemination of trial data on paroxetine in childhood depression was spun 'to minimise any negative commercial impact'. ${ }^{18}$ GSK was accused of underplaying the association between SSRIs and suicidality. The ensuing worldwide media exposure played a role in driving the SSRI suicide controversy. In the process, confidence in the pharmaceutical industry and regulatory authorities decreased significantly. ${ }^{19}$ To date, the controversy remains unsettled, albeit evidence also suggests that SSRIs are useful first-line treatments for depression and most anxiety disorders but exhaustive monitoring is recommended during the initiating phase. $^{20}$

\section{METHODS}

\section{Time frame}

Content analysis was performed on articles published in the period January 2000 to December 2009, including the period in which the regulatory warnings were repeatedly enforced, that is, 2003/2004 and 2007.

\section{Data sources}

Scientific articles were extracted from Embase (compilation of Medline and 2000 extra journals not covered by Medline) using two sets of keywords, that is, first: 'serotonin uptake inhibitor' NOT 'serotonin noradrenalin reuptake inhibitor' AND 'suicidal behavior' or 'automutilation' or 'aggression' AND 'depression'; and second: 'serotonin uptake inhibitor' NOT 'serotonin noradrenalin reuptake inhibitor' AND 'suicide'. The search was limited to 'humans' and 'Dutch' and 'English' language.

Newspaper articles were extracted using the LexisNexis database from a selection of high-circulation newspapers in NL $(\mathrm{n}=6)$ and in the UK $(\mathrm{n}=4)$. The newspapers analysed were De Telegraaf, Algemeen Dagblad, De Volkskrant, NRC Handelsblad, Trouw and Het Parool for NL and The Sun, Daily Mail, The Daily Telegraph and The Times for UK. The newspapers' circulation figures (per country) covered $11 \%$ of each total resident population. ${ }^{21} 22$ Search queries were performed in the language of the papers (Dutch and English). Dutch articles were retrieved using the terms 'antidepressiv!' or 'anti-depressiv!' or 'SSRI!' or 'serotonine!' AND 'zelfmoord!' or 'aggressi!' or 'geweld!' or 'kwaad!' or 'suicid!' AND 'depressi!'. British articles were extracted using the terms 'antidepress!' or 'anti-depress!' or 'SSRI!' or 'serotonin!' AND ‘suicid!' or 'aggressi!' or 'violen!' or 'harm!' AND ‘depressi!'.

\section{Data classification}

All articles addressing SSRIs, depression, suicidal thoughts or suicide as the main topic were eligible for analysis. If that was not the case, such an article was categorised as 'out of context', for example, articles reporting the use of SSRIs to treat premature ejaculation or neuralgia. All scientific and newspaper articles were analysed on the content of full-text, except for scientific articles where the abstract information was regarded as sufficient for categorisation. The 'effect', 'type of article' and 'age group' categories were independently determined for these articles by two researchers.

The 'effect' category was divided into positive, neutral and negative. Articles reporting on positive therapeutic outcomes with no mention of an association between SSRIs and an increased risk on suicidal behaviour were classified as positive. Consequently, articles affirmatively reporting on the association between SSRI use and suicidality, with no mention of positive therapeutic outcomes, were classified as negative. Articles with a balanced message (positive and negative effects) were classified as neutral. The 'type of article' category was defined within scientific journals as: case study 
(represents a descriptive and intensive analysis of an individual patient), research (comprehends study results, such as RCTs (randomised clinical trials), metaanalyses, observational studies (multiple patients), etc), opinion (enclose articles, such as letters to an editor, commentaries, replies, etc) and policy (comprehends articles discussing regulatory-related topics, etc). The definition of 'type of article' in newspapers was based on the nature and elaboration of the news conveyed: interview (comprehends articles where the journalist questioned the interviewee to retrieve information), opinion (comprises articles where the author or journalist portrayed his/her personal perspective), news report (covers general articles with informative news or general journalism), science journalism (comprehends articles presenting scientific information or reports) and policy (comprehends articles discussing regulatoryrelated topics, such as reimbursement, change of indication, etc). Finally, the 'age group' category considered adults (above 18 years old), paediatric (18 years old or younger), both (adult and paediatric) or unspecified.

Scoring discrepancies between the two researchers occurred in approximately $5 \%$ of all the articles. In a case of discrepancy, the categorisation of the article in question was settled by consensus.

\section{Data analysis}

The positive-to-negative ratio of the 'effect' category was calculated (per source, 'type of article' and 'age group' categories). For the statistical analyses, the total count of articles per category was used. Differences in distribution of the 'effect' categories (positive, neutral and negative) were analysed across the sources (Embase, Dutch and/or the UK newspaper articles); type of article and age group were analysed using the Mann-Whitney (two subgroups) or Kruskal-Wallis test (three or more). Statistical significance was defined as $p<0.05$. Statistical analyses were performed using SPSS software (release V.18.0.3).

To assess the publication dynamics, the number of articles (in scientific journals and/or in newspapers) was plotted per year (2000-2010) and per category (effect, type of article or age group).

\section{RESULTS}

A total of 1736 articles were retrieved based on the predefined key word sets. Of these, 1141 articles were fully categorised: 352 scientific, 224 Dutch newspaper articles and 565 British newspaper articles (figure 1). The characteristics of the articles are listed in table 1 .

\section{Publication patterns of the 'effect' category}

Of all 1141 articles (scientific and newspapers), the positive-effect category (39\%) was significantly larger than the negative-effect $(31 \%)$ or the neutral-effect category $(30 \% ; \mathrm{p}<0.001)$. The differentiation of the 'effect' category by source showed that scientific journals were predominantly positive (ratio $=3.5$ ), whereas Dutch and British newspapers coverage of effect was mainly

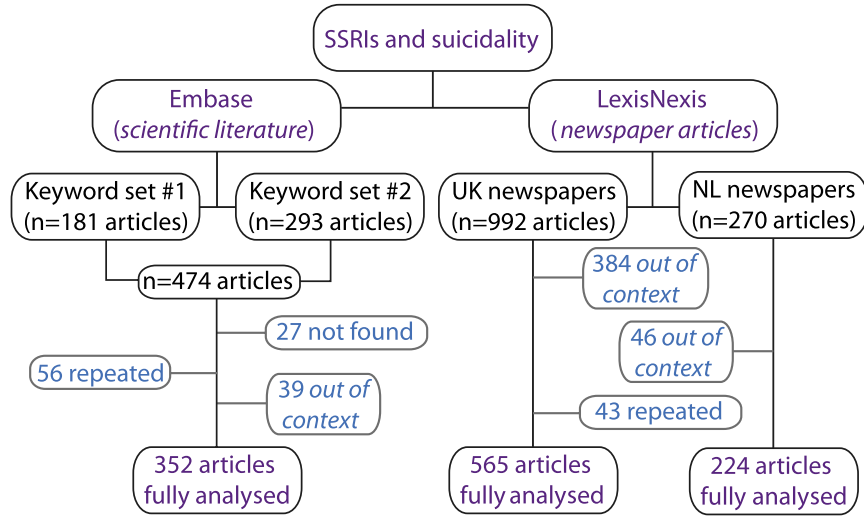

Figure 1 Scheme of the search process performed in the scientific and medical literature and in the Netherlands (NL) and the UK newspapers.

negative (ratios $=0.69-\mathrm{NL}$ and $0.94-\mathrm{UK}$, table 1 ). Statistically significant differences were observed in effect classification for scientific journals and newspapers (both $\mathrm{p}<0.001$ ) but not between NL and the UK dailies $(p=0.116$, table 2$)$.

Although the overall coverage of effect was generally positive in scientific journals, temporal changes were observed in the positive-to-negative effect ratio per year, indicating a less positive-effect trend during 2003/ 2004 and after 2007. Newspaper reporting revealed a similar trend as scientific journals. However, the

Table 1 Characteristics of the 1141 articles in NL and the UK newspapers and in scientific journals (2000-2009)

\begin{tabular}{|c|c|c|c|}
\hline Characteristics & $\begin{array}{l}\text { Scientific } \\
\text { journals } \\
(n=352)\end{array}$ & $\begin{array}{l}\text { NL } \\
\text { newspapers } \\
(n=224)\end{array}$ & $\begin{array}{l}\text { UK } \\
\text { newspapers } \\
(n=565)\end{array}$ \\
\hline \multicolumn{4}{|l|}{ Effect* } \\
\hline Positive & $191(54)$ & 65 (29) & $192(34)$ \\
\hline Neutral & $106(30)$ & 66 (29) & $169(30)$ \\
\hline Negative & $55(16)$ & $93(42)$ & $204(36)$ \\
\hline $\begin{array}{l}\text { Positive-to- } \\
\text { negative ratio }\end{array}$ & 3.5 & 0.69 & 0.94 \\
\hline \multicolumn{4}{|l|}{ Type of article } \\
\hline Case study & $13(4)$ & NA & NA \\
\hline Research & $210(60)$ & NA & NA \\
\hline Opinion & $121(34)$ & $25(11)$ & 107 (19) \\
\hline Policy & $8(2)$ & $11(5)$ & $10(2)$ \\
\hline Interview & NA & 38 (17) & $77(14)$ \\
\hline News report & NA & $110(49)$ & $291(52)$ \\
\hline $\begin{array}{l}\text { Science } \\
\text { journalism }\end{array}$ & NA & $40(18)$ & $80(14)$ \\
\hline \multicolumn{4}{|l|}{ Age group } \\
\hline Adults & $89(25)$ & $128(57)$ & $313(55)$ \\
\hline Paediatric & $108(31)$ & 30 (13) & $92(16)$ \\
\hline Both & $80(23)$ & $32(14)$ & $66(12)$ \\
\hline Unspecified & $75(21)$ & $34(15)$ & $94(17)$ \\
\hline
\end{tabular}

*Statistically significant differences in effect classification were observed between scientific journals and newspapers $(p<0.001)$ but not between NL and the UK dailies $(p=0.116)$.

$\mathrm{NL}$, the Netherlands. 
Table 2 Allocation of effect categories related to types of article and age groups and differentiated by source (NL and the UK newspaper articles combined)

\begin{tabular}{|c|c|c|c|c|c|}
\hline Categories & Positive & Neutral & Negative & $\begin{array}{l}\text { Positive-to- } \\
\text { negative ratio }\end{array}$ & p Value \\
\hline NL newspapers & 65 & 66 & 93 & 0.69 & 0.116 \\
\hline UK newspapers & 192 & 169 & 204 & 0.94 & \\
\hline Scientific journals & 191 & 106 & 55 & 3.50 & $<0.001$ \\
\hline NL and UK newspapers (mixed) & 257 & 235 & 297 & 0.86 & \\
\hline \multicolumn{6}{|l|}{ Type of article } \\
\hline \multicolumn{6}{|l|}{ Scientific journals } \\
\hline Case study & 4 & 4 & 5 & 0.80 & $<0.001$ \\
\hline Research & 144 & 49 & 17 & 8.47 & \\
\hline Opinion & 39 & 49 & 33 & 1.18 & \\
\hline Policy & 3 & 5 & 0 & 3.00 & \\
\hline \multicolumn{6}{|l|}{ Newspapers* } \\
\hline Interview & 69 & 30 & 16 & 4.31 & $<0.001$ \\
\hline News report & 88 & 125 & 188 & 0.47 & \\
\hline Science journalism & 38 & 30 & 52 & 0.73 & \\
\hline Opinion & 60 & 43 & 29 & 2.07 & \\
\hline Policy & 2 & 7 & 12 & 0.17 & \\
\hline \multicolumn{6}{|l|}{ Age group } \\
\hline \multicolumn{6}{|l|}{ Scientific journals } \\
\hline Adults & 70 & 12 & 7 & 10.0 & $<0.001$ \\
\hline Paediatric & 48 & 39 & 21 & 2.29 & \\
\hline Both & 33 & 29 & 18 & 1.83 & \\
\hline Unspecified & 40 & 26 & 9 & 4.44 & \\
\hline \multicolumn{6}{|l|}{ Newspapers } \\
\hline Adults & 176 & 145 & 120 & 1.47 & $<0.001$ \\
\hline Paediatric & 18 & 20 & 84 & 0.21 & \\
\hline Both & 22 & 33 & 43 & 0.51 & \\
\hline Unspecified & 41 & 37 & 50 & 0.82 & \\
\hline
\end{tabular}

positive-to-negative effect ratio per year in newspapers shifted to the negative side from 2003 to 2005 and after 2007 (figure 2B).

\section{Publication patterns of the 'type of article' category}

Scientific journals published generally research articles $(60 \%)$, carrying a positive-effect message (ratio $=8.5$, table 2). To a lesser extent, scientific journals published opinion articles $(34 \%)$, which conveyed an overall positive-effect message (ratio $=1.2$, table 2 ). However, scientific opinion articles displayed major temporal changes in the positive-to-negative effect ratio following regulatory warnings, showing more negative-effect articles. Differences of 'effect' distributions related to 'types of article' were statistically significant $(\mathrm{p}<0.001$, table 2$)$.

Newspapers published mainly news report articles $(50.5 \%)$ and carried an overall negative-effect message $($ ratio $=0.5$, table 2$)$. A similar negative-effect trend was measured in scientific journalism articles (ratio $=0.7)$. Newspaper opinion articles also portrayed an overall positive-effect message (ratio=2.1), as observed for opinion articles in scientific journals (ratio=1.2, table 2 ). Major temporal changes in the positive-to-negative effect ratio of newspaper articles were visible in the period of regulatory warnings (2002-2005 and
2007-2008, figure 2B). Differences between effect distributions related to 'types of article' were statistically significant in the accumulated newspaper articles group, the UK newspaper articles $(\mathrm{p}<0.001)$ and NL newspaper articles $(\mathrm{p}=0.011)$.

\section{Publication patterns of the 'age group' category}

Scientific journals reported more frequently on paediatrics $(31 \%)$ than on adults $(25 \% ; \mathrm{p}<0.001)$. Articles on adults were notably more positive concerning effect compared with paediatric articles (ratios $=10$ and 2.3, table 2).

Newspapers paid more attention to adults (56\%) than paediatrics $(15 \%$, table 1$)$. Reporting trend for articles on adults was primarily positive about effect, whereas those on paediatrics were mainly negative ( ratios $=1.5$ and 0.2). Significant differences were found between effect distributions in newspapers related to age group $(\mathrm{p}<0.001)$. Reporting patterns between NL and the UK dailies were comparable in all three categories $(p=0.116$, table 2).

Articles on paediatrics in scientific journals and in newspapers displayed similar publication dynamics, that is, a significant peak in 2004, following the warnings. The publication dynamics of articles on adults in scientific 
Figure 2 (A) Effect messages (positive and negative) organised along the research period, per year (2000-2009) and according to the source (scientific-medical journals and newspapers). (B) The natural logarithm of the positive-to-negative ratio was calculated and also plotted for the accumulated scientific-medical articles (green line), accumulated newspaper articles (red line) and solely research articles from the scientific-medical literature (dark blue line). *The grey zone of the regulatory warnings were issued. ${ }^{* *}$ Articles with a positiveeffect trend are located above zero, while articles conveying a negative-effect trend are located underneath zero. illustrates the period where most
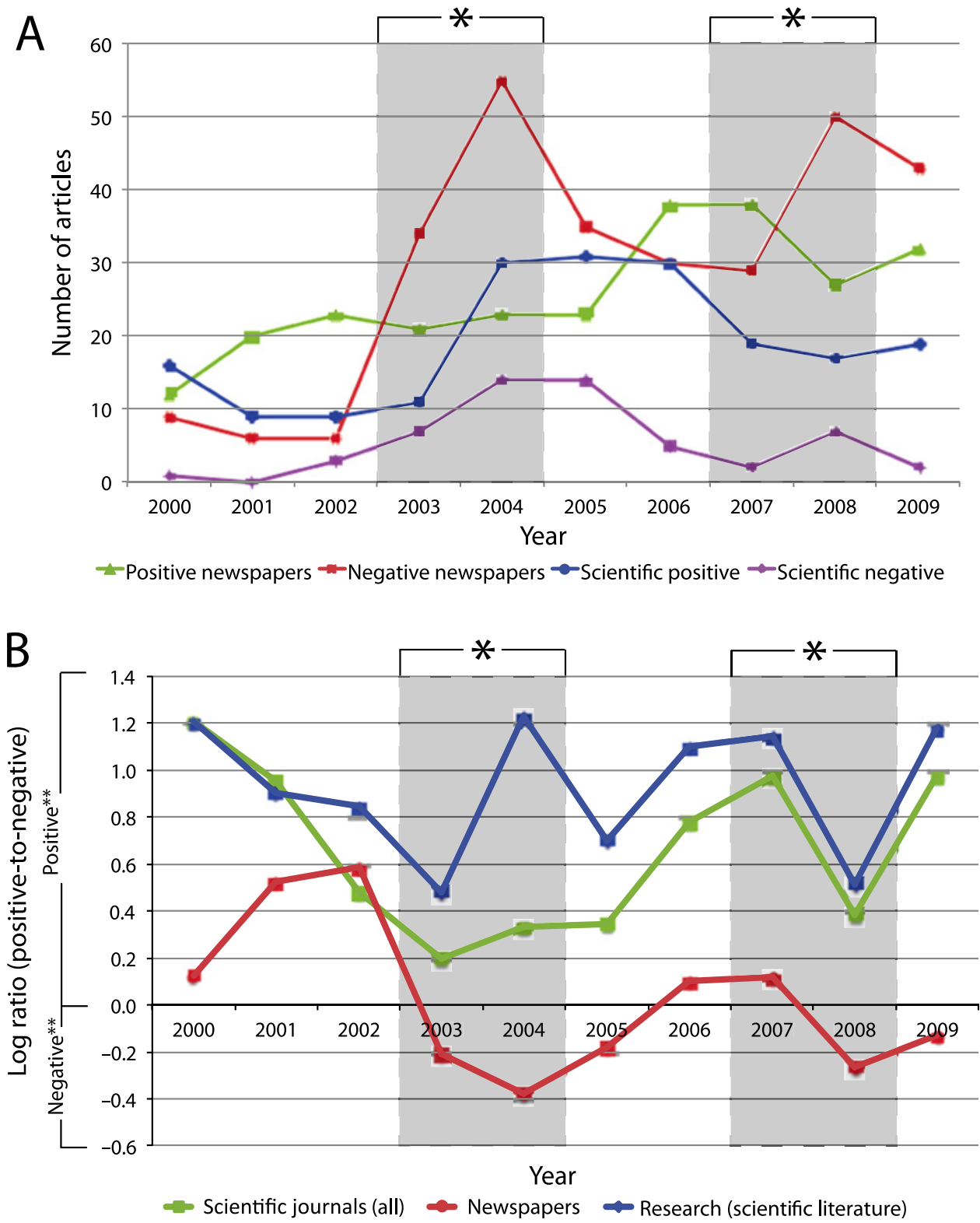

journals and newspapers also showed a similar pattern. Thereafter, newspaper articles on adults continued to increase until 2010, while their scientific counterparts remained more or less stable (figure 3 ).

\section{DISCUSSION}

This study assessed the characteristics and dynamics of SSRIs and suicidality coverage by scientific and medical journals in general and newspapers in NL and the UK from 2000 to 2010. Scientific journals published predominantly research articles about positive therapeutic outcomes with little mention of an association between SSRIs and suicidality, particularly in adults. Despite different ethnic backgrounds (eg, tabloid culture in the UK, among others) and language, newspaper reporting trends in NL and the UK were comparable and were overall negative regarding the therapeutic effect of SSRIs in paediatrics, while positive-effect reporting prevailed for adults.
The present study has several limitations. It covered $11 \%$ of the total population per country based on newspaper circulation figures. Nevertheless, the random sample is representative $(\mathrm{n}=789$ newspaper articles) given the aim to ascertain differences (in terms of numbers, categories and timing) between negative and positive newspaper and journal articles on SSRIs and suicidality. The categories 'effect' and 'type of article' might be limited by our definition, and their interpretation could differ between readers. We attempted to avoid subjectivity by analysing the data independently by two researchers. We achieved $>95 \%$ agreements during article categorisation (effect, type of article and age group categories). We did not, however, ascertain the context of the articles in terms of construction of the newspaper and opinion articles from its original source. Neither did we explore other forms of media coverage (television, radio, magazines or the internet). The content analysis method used in this 
Figure 3 Articles indexed into age groups (paediatric and adult) in scientific-medical journals and in newspapers from 2000 to 2009. The scale of newspaper articles on adults is portrayed on the right $y$-axis. *The grey zone illustrates the period where most of the regulatory warnings were issued.

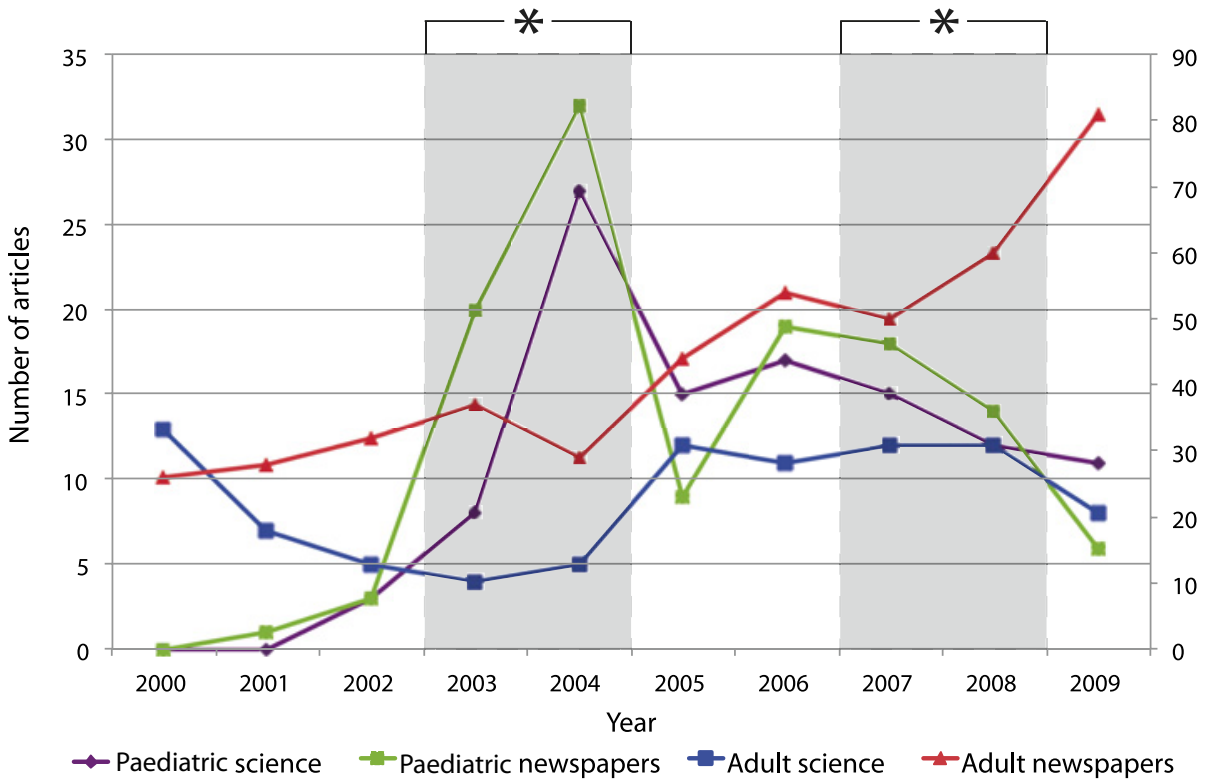

study does not allow for these additional more complex queries.

Our results showing a positive publication tendency in scientific journals are consistent with the previous work, which demonstrated that antidepressant trials with a positive outcome were published more often than those with negative outcomes. ${ }^{23}$ This positive publication tendency continued even after the regulatory warnings and could potentially leave physicians with a biased view of the medications that they are prescribing to patients. Studies questioning these warnings and the possible disservice they did to public health (eg, the possible inverse association between SSRIs prescriptions and suicidality or the decline in treatment of depression in paediatrics) contributed to this post-warning positive-effect trend. ${ }^{16} 17$ On the other hand, this positive publication tendency in scientific journals does not seem to prevent the dissemination of bad news about medications. For instance, science journalism articles (newspapers) that presented a negative publication tendency regarding SSRIs (ratio $=0.7$ ) could not be related to the positive publication tendency found in scientific journals. These findings indicate that either newspaper journalists may selectively report scientific outcomes to the public, as also stated in the CHMP assessment report on antidepressants, ${ }^{24}$ or that controversial topics might be selected to increase readership. 4102526 Such practices might generate confusion, since the translation of evidence-based medicine to the public is not uniform, ${ }^{251227}$ and may have implications for patients compliance with medications, willingness to see physicians and trust in the doctor-patient relationship. However, scientific and medical journals might also do disfavour to the scientific community by favouring positive outcome studies, thus limiting the journalists' sources of accurate and critic information to communicate to the public new scientific and medical evidence.

The uncertainties regarding the SSRIs' benefit/risk balance, primarily in paediatrics, have led to the restric- tion of almost all SSRIs under 18-year-olds in 2003 and further restrictions for young adults (18-24-year-old) in $2007 .^{13-1528}$ In the same periods, our data revealed shifts towards negative-effect reporting trends in scientific and newspaper articles on paediatrics and opinion articles. The timing between the warnings and the observed increase in articles substantiate the possible influence of warnings on media publication trends. Moreover, this increment in the number of articles suggests that newspapers informed the public about this particular drug safety event in a timely fashion. Studies have underlined the relevance of informing the public about medical news within a suitable time frame. ${ }^{6}{ }^{29}$ However, these studies only focused on a subset of scientific journals, whereas we did not discriminate among scientific journals. A balance between timely coverage, consistent and adequate information is fundamental when reporting on drug safety controversies. Ideally, this balance should be the result of an open dialogue between healthcare practitioners, academia, governmental agencies, the pharmaceutical industry, journalists and the public. However difficult, educating the public properly and on time about the benefits and the risks of medicines will help to maintain public trust during unsettling periods. ${ }^{30}$

Finally, the possible implications of the discovered tendencies in scientific journals and newspapers for patients and doctors have not been addressed in this paper. It has been shown that news media reports (on suicide or related to suicide) have an influence on suicidal behaviour and on drug usage. ${ }^{31} 32$ It might be valuable in this regard to determine the long-term influence of media coverage and the regulatory warnings on prescription patterns.

\section{CONCLUSIONS}

Our study of the SSRIs and suicidality controversy showed several publication tendencies in scientific journals and newspapers. We identified a positive publication 
tendency inherent in journal research articles, which could potentially affect doctors' assessment of the safety and effectiveness of the medications that they are prescribing to patients. This apparent positive publication bias in scientific journals, however, does not seem to prevent the dissemination of bad news about medications. The occurrence of good or bad news in scientific journals and newspapers was found to be dependent on the news category or type of article. Opinion reports in scientific journals did not differ significantly in the nature and timing of reporting from opinion articles in Dutch and British dailies. Differences between the Dutch and British newspaper reporting patterns were minor. The negative tendency present in Dutch and British newspapers was perceivable in the paediatrics group and during the warnings, indicating that newspapers have informed the public about this drug safety controversy on time. It also shows that a proactive and transparent risk communication strategy of regulatory offices and the pharmaceutical industry might pay off in the long run for reporting on the benefits and risks of medications.

Competing interests JAMR is part-time professor at the Utrecht University and vice president external scientific collaborations for GlaxoSmithKline (GSK) in Europe and holds stock in GSK. All other authors declare no personal conflict of interest relevant to the subject matter or materials discussed in the manuscript. This study was performed in the context of the Escher project (T6-202), a project of the Dutch Top Institute Pharma. The Division of Pharmacoepidemiology and Clinical Pharmacology, employing authors JFH, AKM-T, SVB, JAMR and TP, has received unrestricted funding for pharmacoepidemiological research from GSK, the private- and public-funded Top Institute Pharma (http://www.tipharma.nl, includes co-funding from universities, government and industry), the Dutch Medicines Evaluation Board and the Dutch Ministry of Health.

Contributors All authors were involved in the design of the study, review of earlier versions of the manuscript and providing final approval for submission. JFH was responsible for the collection, analysis (also statistical) and interpretation of the data, as well as drafting and revising the manuscript. TP was responsible for the analysis and interpretation of the data, drafting supervision and revision. SVB provided support with the statistical analyses, as well.

Provenance and peer review Not commissioned; externally peer reviewed.

Data sharing statement Data deposited at Dryad: doi:10.5061/dryad. gm2534t7.

\section{REFERENCES}

1. Wilson A, Bonevski B, Jones A, et al. Media reporting of health interventions: signs of improvement, but major problems persist. PLoS One 2009;4:e4831.

2. Moynihan R, Bero L, Ross-Degnan D, et al. Coverage by the news media of the benefits and risks of medications. $N$ Engl $J$ Med 2000;342:1645-50.

3. Ries NM, Rachul C, Caulfield T. Newspaper reporting on legislative and policy interventions to address obesity: United States, Canada, and the United Kingdom. J Public Health Policy 2011;32:73-90.

4. Bartlett C, Sterne J, Egger M. What is newsworthy? Longitudinal study of the reporting of medical research in two British newspapers. BMJ 2002;325:81-4.

5. Lai WY, Lane T. Characteristics of medical research news reported on front pages of newspapers. PLoS One 2009;4:e6103.

6. Canales MK, Breslau ES, Nelson DE, et al. Did news reporters get it right? Translation of the 2002 hormone study findings. Am J Prev Med 2008:34:61-8.

7. Dentzer S. Communicating medical news - pitfalls of health care journalism. N Engl J Med 2009;360:1-3.
8. Archer DF. Medical decisions regarding hormone therapy for menopausal women are significantly influenced by the media. Pharmacoepidemiol Drug Saf 2007;16:28-31.

9. Williams D, Kelly A, Feely J. Influence of media and regulatory changes on prescribing of Cotrimoxazole and Trimethoprim in Ireland. Pharmacoepidemiol Drug Saf 2000;9:313-17.

10. Mebane FE. The importance of news media in pharmaceutical risk communication: proceedings of a workshop. Pharmacoepidemiol Drug Saf 2005;14:297-306.

11. Grilli R, Ramsay C, Minozzi S. Mass media interventions: effects on health services utilisation. Cochrane Database Syst Rev 2002;(1): CD000389.

12. Danovaro-Holliday MC, Wood AL, LeBaron CW. Rotavirus vaccine and the news media, 1987-2001. JAMA 2002;287:1455-62.

13. FDA. Suicidality in Children and Adolescents Being Treated With Antidepressant Medications. Rockville, MD: Department of Health and Human Services, 2004. http://www.fda.gov/Drugs/DrugSafety/ PostmarketDrugSafetylnformationforPatientsandProviders/ DrugSafetyInformationforHeathcareProfessionals/

PublicHealthAdvisories/ucm161679.htm (accessed 20 Jan 2011).

14. EMA. European Medicines Agency Finalises Review of Antidepressants in Children and Adolescents. London: EMA, 2005. http://www.ema.europa.eu/ema/index.jsp?curl=pages/news and_events/news/2009/12/news_detail_000882.jsp\&murl= menus/news_and_events/news_and_events.jsp\&mid= WC0b01ac058004d5c1 (accessed 4 Feb 2011).

15. MHRA. Report of the CSM Expert Working Group on the Safety of Selective Serotonin Reuptake Inhibitor Antidepressants. London: Committee on Safety of Medicines, 2004. http://www.ema.europa.eu/ docs/en_GB/document_library/Report/2010/01/WC500054061.pdf (accessed 4 Feb 2011).

16. Cheung A, Sacks D, Dewa CS, et al. Paediatric prescribing practices and the FDA Black-box warning on antidepressants. J Dev Behav Pediatr 2008;29:213-15.

17. Wheeler BW, Gunnell D, Metcalfe C, et al. The population impact on incidence of suicide and non-fatal self harm of regulatory action against the use of selective serotonin reuptake inhibitors in under $18 \mathrm{~s}$ in the United Kingdom: ecological study. BMJ 2008:336:542-5.

18. BBC. Panorama: The Secrets of Seroxat. London: BBC, 2002. http:// news.bbc.co.uk/panorama/hi/front_page/newsid_8425000/8425414. stm (accessed 7 Feb 2011)

19. Olsen AK, Whalen MD. Public perceptions of the pharmaceutical industry and drug safety: implications for the pharmacovigilance professional and the culture of safety. Drug Saf 2009;32:805-10.

20. Ravindran LN, Stein MB. The pharmacologic treatment of anxiety disorders: a review of progress. J Clin Psychiatry 2011;71:839-54.

21. Department of statistics UK. 2010. http://www.statistics.gov.uk/cci/ nugget.asp? id=6 (accessed 20 Aug 2010).

22. CBS. Bevolkinsteller (Centrale Bureau van Statistiek). 2010. http:// www.cbs.nl/en-GB/menu/themas/bevolking/cijfers/extra/ bevolkingsteller.htm (accessed 20 Aug 2010).

23. Turner EH, Matthews AM, Linardatos E, et al. Selective publication of antidepressant trials and its influence on apparent efficacy. $N$ Engl $J$ Med 2008;358:252-60.

24. EMA. CHMP Assessment Report on Antidepressants. London: EMA 2008. http://www.ema.europa.eu/docs/en_GB/document_library/ Report/2010/01/WC500054061.pdf (accessed 7 Feb 2011).

25. Franklin B, Hamer M, Hanna M, et al. Key Concepts in Journalism Studies. London: Sage, 2005.

26. Iggers J. Good news, bad news: journalism ethics and the public interest. Boulder, Colorado: Westview press, 1999

27. Koren G, Klein N. Bias against negative studies in newspaper reports of medical research. JAMA 1991;266:1824-6.

28. FDA. Antidepressant Use in Children, Adolescents, and Adults. Rockville, MD: Department of Health and Human Services, 2007. http://www.fda.gov/Drugs/DrugSafety/InformationbyDrugClass/ ucm096273.htm (accessed 7 Feb 2011).

29. Stryker JE. Reporting medical information: effects of press releases and newsworthiness on medical journal articles' visibility in the news media. Prev Med 2002;35:519-30.

30. Karacsony A, Rosenbaum J. Recapturing the Vision: Restoring Trust in the Pharmaceutical Industry By Translating Expectations into Actions. 2007. http://www.pwc.com/gx/en/pharma-life-sciences/ pharmaceutical-industry-thought-leadership.jhtml (accessed 21 Jul 2011).

31. Pirkis J, Blood RW. Suicide and the media. Part I: Reportage in nonfictional media. Crisis 2001;22:146-54.

32. Martin RM, May M, Gunnell D. Did intense adverse media publicity impact on prescribing of paroxetine and the notification of suspected adverse drug reactions? Analysis of routine databases, 2001-2004. Br J Clin Pharmacol 2006;61:224-8. 